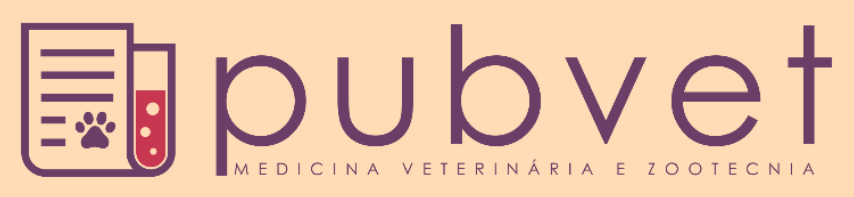

https://doi.org/10.31533/pubvet.v14n1a497.1-5

\title{
Elaboração e caracterização do pão enriquecido com farinha a base de buriti (Mauritia flexuosa L.)
}

\author{
Rodrigo Chermont Gomes ${ }^{1 * \bullet}$, Kriscya Lorena Frazão Coimbra ${ }^{1}$, Anne do Socorro Santos da \\ Silva $^{2}{ }^{\circ}$, Antonio Carlos Souza da Silva Júnior ${ }^{2}$ \\ ${ }^{1}$ Acadêmico(a) de Nutrição da Faculdade Estácio de Macapá, Macapá-AP Brasil. \\ ${ }^{2}$ Pesquisador(a) do Instituto de Pesquisas Científicas e Tecnológicas do Estado do Amapá- IEPA, Núcleo de Ciência e Tecnologia de \\ Alimentos. Macapá-AP Brasil. \\ *Autor para correspondência,E-mail: rodrigochermont93@gmail.com
}

Resumo. O buritizeiro é uma palmeira de um único caule, com altura aproximada de 28 a 35 metros. $\mathrm{O}$ fruto possui tamanho de 4 a $7 \mathrm{~cm}$ com polpa de cor alaranjada, rica em vitaminas A, B, C, minerais como cálcio e ferro, além de proteínas, ácidos graxos oléicos, palmíticos, carotenóides e polifenóis. Objetivou-se nesta pesquisa elaborar e caracterizar o pão enriquecido com farinha a base de buriti (Mauritia Flexuosa $L$ ). Inicialmente foram coletados frutos in natura no município de Afuá, Pará e transportados para o Núcleo de Ciência e Tecnologia de Alimentos do Instituto de Pesquisas Científicas e Tecnológicas do Estado do Amapá (IEPA). Efetuou-se o despolpamento dos frutos, produção da farinha e pão e realização da análise físico-química da composição centesimal de (umidade, cinzas, proteínas, lipídeos, carboidratos) e composto químicos (antocianina e flavonóides) da polpa, farinha e pão. Além disso, foram realizadas as análises microbiológicas (Staphylococcus, Salmonella e Coliformes Termotolerantes) da farinha e do pão de buriti. Pela caracterização de análises físico-química do pão obteve-se os seguintes resultados: proteína $11,35 \pm 0,02 \%$, lipídeos $7,19 \pm 0,01 \%$, carboidratos $43,13, \%$ de umidade $35,78 \pm$ $0,03 \%$, cinzas $2,55 \pm 0,002 \%$, antocianina $0,130 \pm 0,009 \%$, flavonóides $0,03 \pm 0,004 \%$. O pão a base de farinha de buriti demonstrou ser apto para o consumo. As análises microbiológicas detectaram valores recomendados por lei.

Palavras-chave: Antocianina, buriti, flavonoides, pão

\section{Preparation and characterization of bread enriched with basin flour Mauritia flexuosa $\mathrm{L}$.}

\begin{abstract}
Mauritia Flexuosa L is a single-stemmed palm, with a height of about 28 to 35 meters. The fruit has a size of 4 to $7 \mathrm{~cm}$ with orange colored pulp, rich in vitamins $\mathrm{A}, \mathrm{B}, \mathrm{C}$, minerals such as calcium and iron, as well as proteins, oleic fatty acids, palmitic, carotenoids and polyphenols. The objective of this research was to elaborate and characterize the bread enriched with flour based on M. Flexuosa L. Initially fresh fruits were collected in the city of Afuá, Pará and transported to the Nucleus of Food Science and Technology of the Institute of Scientific and Technological Research of the State of Amapá (IEPA). The fruit pulp, flour and bread production were carried out and the physicochemical analysis of the centesimal composition of (moisture, ashes, proteins, lipids, carbohydrates) and chemical compounds (anthocyanin and flavonoids) of pulp, flour and bread. In addition, the microbiological analyzes (Staphylococcus, Salmonella and Coliformes Termotolerantes) of the flour and M. Flexuosa L bread was carried out. By the characterization of the physical-chemical analysis of the bread, the following results were obtained: protein $11.35 \pm 0.02 \%$, lipids $7.19 \pm 0.01 \%$, carbohydrate
\end{abstract}


$43.13 \%$, moisture $35.78 \pm 0.03 \%$, ash $2.55 \pm 0.002 \%$, anthocyanin $0.130 \pm 0.009 \%$ and flavonoids $0.03 \pm 0.004 \%$. The bread made from M. Flexuosa $\mathrm{L}$ flour proved to be fit for consumption, microbiological analyzes detected values recommended by law.

Keywords: Anthocyanin, buriti, flavonoids, bread

\section{Elaboración y caracterización del pan enriquecido con farina a base de Mauritia flexuosa L.}

Resumen. El Mauritia Flexuosa L es una palmera de un solo tallo, con una altura aproximada de 28 a 35 metros. El fruto tiene un tamaño de 4 a $7 \mathrm{~cm}$ con pulpa de color anaranjado, rica en vitaminas A, B, C, minerales como el calcio y el hierro, además de proteínas, ácidos grasos oleicos, palmíticos, carotenoides y poli fenoles. Se objetivó en esta investigación elaborar y caracterizar el pan enriquecido con harina a base de Mauritia Flexuosa L. Inicialmente fueron recolectados frutos in natura en el municipio de Afuá, Pará y transportados al Núcleo de Ciencia y Tecnología de Alimentos del Instituto de Investigaciones Científicas y Tecnológicas del Estado de Amapá (IEPA). Se realizó el despolpamiento de los frutos, producción de la harina y pan, y realización del análisis físico-químico de la composición centesimal de (humedad, cenizas, proteínas, lípidos, carbohidratos) y compuestos químicos (antocianina y flavonoides) de la pulpa, harina y pan. Además, se realizaron los análisis microbiológicos (Staphylococcus, Salmonella y Coliformes Termotolerantes) de la harina y pan de Mauritia Flexuosa L. A través de la caracterización de análisis físico-químico del pan se obtuvieron los siguientes resultados: proteína $11,35 \pm 0,02 \%$, lípidos $7,19 \pm 0,01 \%$, carbohidrato $43,13 \%$, humedad $35,78 \pm 0,03 \%$, cenizas $2,55 \pm 0,002 \%$, antocianina $0,130 \pm 0,009 \%$ y flavonoides $0,03 \pm 0,004 \%$. El pan a base de harina de Mauritia Flexuosa L demostró ser apto para el consumo, los análisis microbiológicos detectaron valores recomendados por ley.

Palabras clave: Antocianina, buriti, flavonoides, pan

\section{Introdução}

O Brasil possui uma variedade de plantas que são fontes de vitaminas e compostos vitais para o ser humano, no qual se destaca o buriti. O buriti é uma das plantas símbolo do cerrado e sua diversidade de usos tornou-o conhecido como a "Árvore da Vida" (Sampaio, 2011). Segundo Sampaio (2011) o Buriti (Mauritia flexuosa L.) é uma palmeira que pertence à família Palmae ou Arecaceae e a subfamília Lepidocarycideae, encontrado no Brasil especialmente na Amazônia. Essa larga proliferação da planta torna o fruto abundante e acessível, que por falta de estudos, ainda não são largamente exploradas as suas potencialidades.

O fruto do buriti possui potencial para a produção de alimentos ricos em vitaminas e antioxidantes (Batista et al., 2012). Dela são confeccionados produtos que são utilizados em eventos culturais, no diaa-dia dos agroextrativistas e também, comercializados para a geração de renda das famílias (Sampaio \& Carrazza, 2012). O buriti além de rico em nutrientes pode ser utilizado como fonte de renda na produção de variados tipos de alimentos (Saraiva \& Sawyer, 2007).

A polpa possui quantidades consideráveis de carotenóides, polifenóis e ácido ascórbico, apresentando potencial para ser utilizado na prevenção de doenças causadas pelo estresse oxidativo (Manhães, 2007). Também pode ser produzida a farinha, que é uma das opções de produtos derivados da polpa de buriti, podendo servir como valor agregado, gerando importantes oportunidades econômicas para os pequenos e médios produtores, além de ser um alimento rico em atividade oxidante (Lage, 2014).

O objetivo do presente trabalho foi elaborar e caracterizar o pão enriquecido com farinha a base de buriti, pela determinação da composição centesimal da polpa, farinha e pão (umidade, cinzas, proteínas, lipídeos, carboidratos) e compostos químicos (Antocianina e flavonóides) além da análise microbiológica, tornando-o uma alternativa segura para o consumo alimentar de qualidade nutricional. 


\section{Material e métodos}

Para realização das análises, os frutos foram colhidos in natura na comunidade São Benedito, às margens do Rio Amazonas, localizado no município de Afuá, Pará (Figuira 1). Após a coleta, os frutos foram levados para o Núcleo de Ciência e Tecnologia de Alimentos do Instituto de Pesquisas Científicas e Tecnológicas do Estado do Amapá (IEPA), onde foram lavados em água corrente e higienizados a 200ppm de hipoclorito de sódio por 10 minutos.

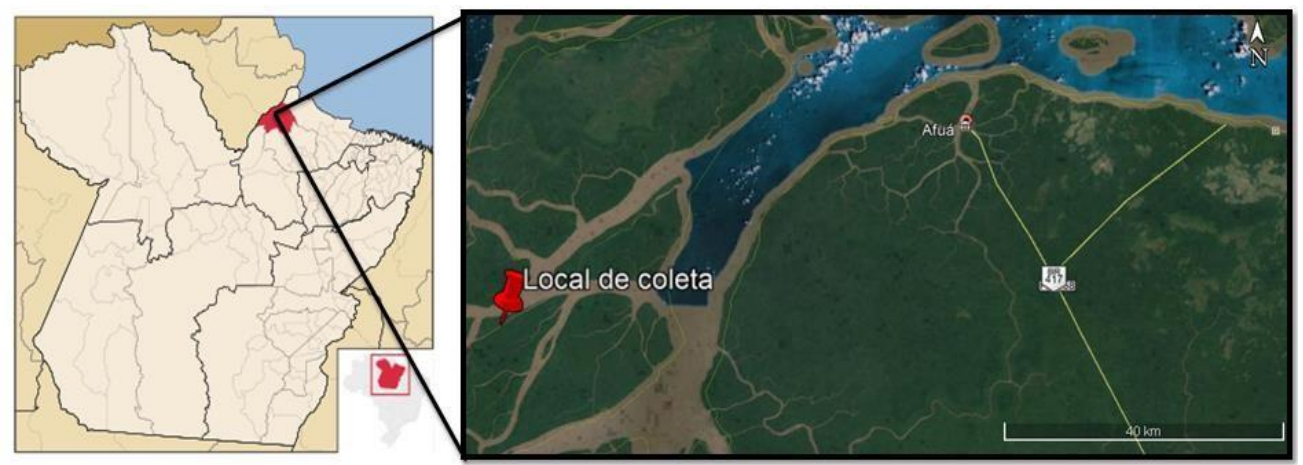

Figura 1. Mapa de localização do ponto de coleta. Fonte: Google Earth. Adaptado (2019).

O material botânico foi depositado no herbário amapaense segundo o parecer $\mathrm{n}^{\circ}$ 09/2019 HAMAB/NUBIO/IEPA: Mauritia flexuosa L.f. Material examinado: Brasil, Pará, Afuá, Comunidade São Benedito, Rio Amazonas, 06.VI.2019, R. C. GOMES, 01 (HAMAB).

Foi realizado o processo de despolpamento, produção da farinha até a fabricação do pão, como mostrado no fluxograma (Figura 2).
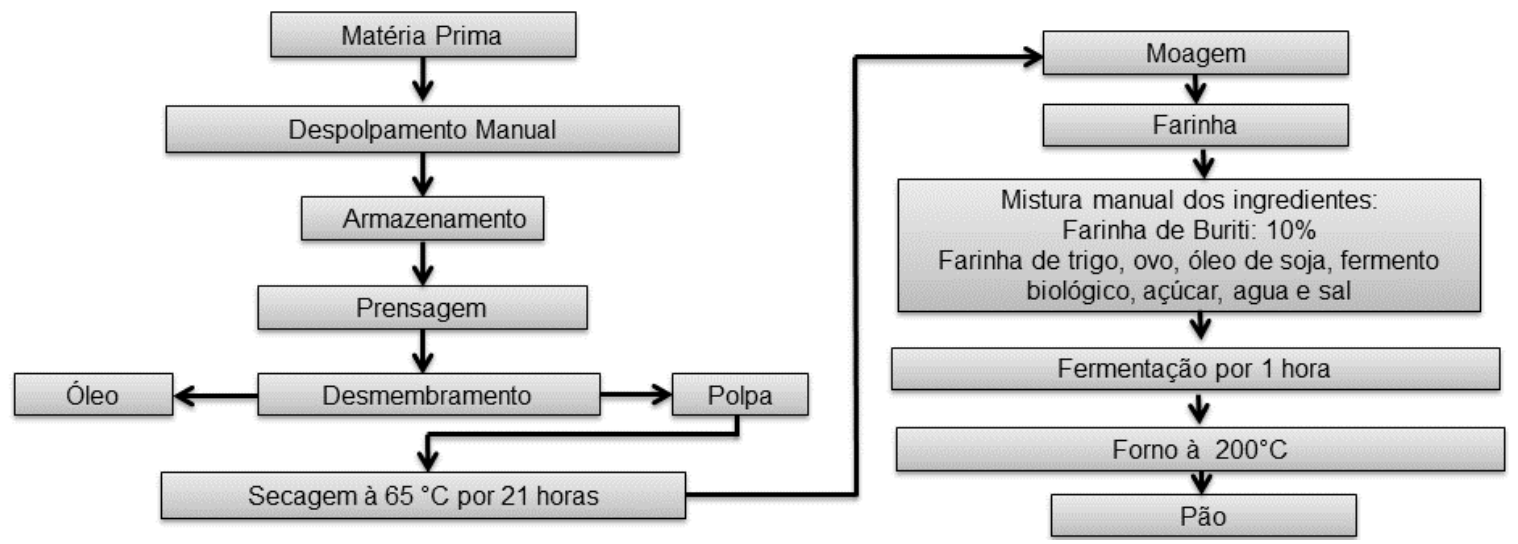

Figura 2. Fluxograma do processo de elaboração da Farinha e Pão do fruto do buriti.

A figura 2 apresenta o processo de elaboração do pão à base da farinha de buriti, onde após a higienização da matéria prima foi realizado o despolpamento manual com faca doméstica. A polpa foi armazenada em sacos plásticos estéreis envolvidos no papel alumínio e congelada por 24 horas. Após esse tempo foi efetuado o descongelamento e encaminhada para a prensa, extraindo o excesso de óleo. Em seguida foi direcionada para secagem em estufa na temperatura de $65^{\circ} \mathrm{C}$, retirando umidade com teor $12 \%$ por $21 \mathrm{~h}$. Posteriormente, foi levada para o moinho para obtenção da farinha. Utilizou-se uma tigela para mistura manual dos seguintes ingredientes: farinha de buriti e trigo, fermento biológico, açúcar, ovo, óleo de soja, água e sal a gosto, sovando e deixando-a fermentar por 1 hora até crescer. Por fim, levada para assar em forno industrial médio à $200^{\circ} \mathrm{C}$, pré-aquecido por aproximadamente 40 minutos (Figura 3).

Procederam-se as análises da composição centesimal de umidade, cinzas, proteínas (Método de Kjeldahl, seguindo as etapas de digestão, destilação e titulação), lipídeos (Método de Bligh-Dyer pela extração de solvente a frio), sequenciando a determinação de carboidratos obtidos pelo cálculo de diferenciação através da equação $\mathrm{E}=100-(\mathrm{A}+\mathrm{B}+\mathrm{C}+\mathrm{D})$, onde $\mathrm{E}=$ carboidrato; $\mathrm{A}$ = proteína total; $\mathrm{B}=$ 
lipídeos; $\mathrm{C}=$ umidade; $\mathrm{D}=$ resíduo mineral fixo, de acordo com o (Pregnolatto \& Pregnolatto, 1985) e compostos químicos (antocianina e flavonóides) de acordo com o método descrito por Francis (1982) pelo espectrofotômetro UV.
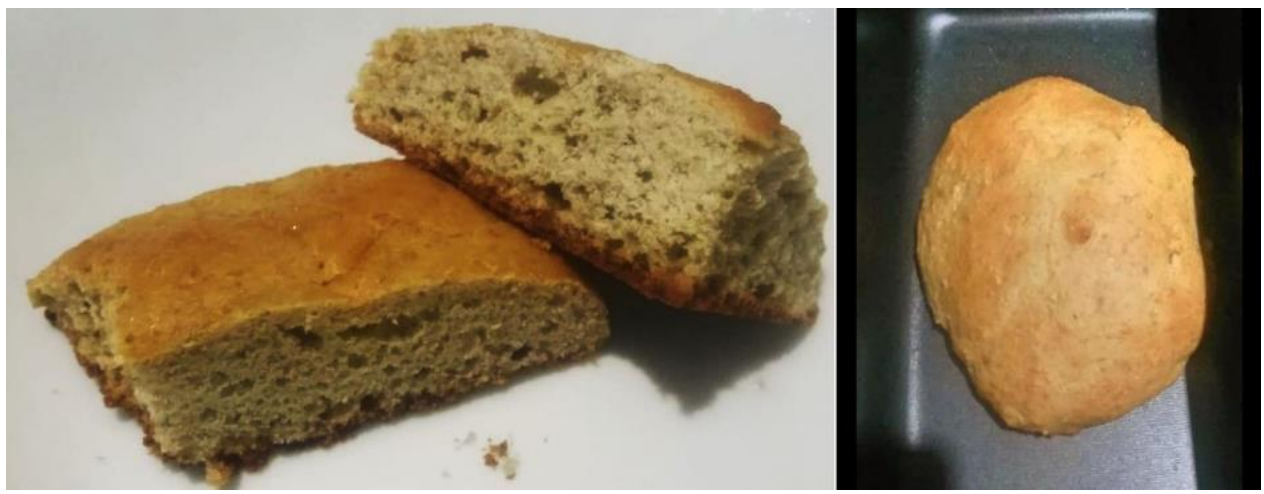

Figura 3. Pão à base da Farinha de Buriti.

\section{Resultados e discussão}

Os resultados das análises de composição química estão explícitos na Tabela 1, indicando a quantidade de cada nutriente encontrado na polpa, farinha e pão de buriti.

Tabela 1. Resultados das análises de composição quimica da polpa, farinha e pão de Buriti.

\begin{tabular}{lcccc}
\hline Análises & Polpa & ${ }^{2}$ Farinha & Pão & ${ }^{2}$ Lage $\left.(2014)\right)$ \\
\hline${ }^{1}$ Proteína & $5,45 \pm 0,02$ & $9,31 \pm 0,01$ & $11,35 \pm 0,02$ & $4,85 \mathrm{~g}$ \\
${ }^{1}$ Lipídeos & $6,87 \pm 0,01$ & $19,8 \pm 0,01$ & $7,19 \pm 0,01$ & $55,5 \mathrm{~g}$ \\
Carboidratos & 25,13 & 61,24 & 43,13 & - \\
${ }^{1}$ Umidade & $60,33 \pm 0,018$ & $5,65 \pm 0,00$ & $35,78 \pm 0,03$ & $4,60 \mathrm{~g}$ \\
${ }^{1}$ Cinzas & $2,22 \pm 0,01$ & $4,0 \pm 0,002$ & $2,55 \pm 0,002$ & $2,10 \mathrm{~g}$ \\
${ }^{1}$ Antocianina & $0,109 \pm 0,009$ & $0,63 \pm 0,107$ & $0,130 \pm 0,009$ & - \\
${ }^{1}$ Flavonoides & $0,280 \pm 0,038$ & $0,58 \pm 0,045$ & $0,03 \pm 0,004$ & - \\
\hline
\end{tabular}

${ }^{1}$ Média \pm Desvio Padrão ; ${ }^{2}$ Comparativo da farinha com Lage (2014).

Utilizou-se o Microsoft Office Excel 2007 para cálculos estatísticos de média e desvio padrão. Realizou-se a análise microbiológica de Coliformes termotolerantes, Staphylococcus coagulase positiva e Salmonella sp, da farinha e pão de buriti, de acordo com a metodologia de Silva et al. (2005) e segundo a legislação vigente (BRASIL, 2001) onde foram obtidos os resultados apresentados na Tabela 2.

A polpa utilizada para a produção da farinha foi submetida à secagem em estufa, para diminuição de umidade, respeitando o padrão de identidade 13,0\% segundo BRASIL (2005). Devido ao tratamento térmico teve como resultado na farinha o aumento no valor de lipídeos em torno 19,8 $\pm 0,01$ e proteína $9,31 \pm 0,01$. No entanto, a polpa in natura possui valores inferiores de 5,45 $\pm 0,02$ de proteína e 6,87 \pm 0,01 lipídeos. Enquanto isso, Lage (2014) obteve valor de 55,5 gramas de lipídeos e 4,85 gramas de proteína em $100 \mathrm{~g}$ da farinha. Sendo assim, ressalta-se que os resultados das análises podem ter infuenciado devido às diferentes regiões, solos, safra do fruto e o método de extração de lipídios.

Em relação aos valores de carboidrato na farinha de 61,24 e no pão 43,13, supõe-se que essa diferença entre o produto e co-bproduto ocorreu devido à utilização de outros ingredientes, e mais $10 \%$ da farinha de buriti na formulação do pão. Enquanto a polpa detectou o menor valor entre as amostras de 25,1.

A composição centesimal atestou valores de antocianina de $0,109 \pm 0,009$ na polpa e 0,63 $\pm 0,107$ na farinha e 2,55 $\pm 0,002$ no pão. Os baixos valores podem ter influência na coloração da polpa do fruto de buriti. Este importante composto químico é encontrado em maiores quantidades em frutos de cor roxa, o que pode ter diferenciado do buriti que possiu polpa de coloração alaranjada.

$\mathrm{Na}$ análise de flavonóides foi encontrada $0,280 \pm 0,038$ na polpa, $0,58 \pm 0,045$ na farinha e $0,03 \pm$ 0,004 no pão de buriti, ressaltando que o fruto não indica ser rico em antocianinas e flavonoides, porém rico em beta caroteno. 
Tabela 2. Análises microbiológica da farinha e pão de briti

\begin{tabular}{lccc}
\hline & ${ }^{1}$ Coliforme termo** (NMP/g) & ${ }^{2}$ Staphylococcus C.P. $* * *(\mathrm{UFC} / \mathrm{g})$ & ${ }^{3}$ Salmonellasp. \\
\hline Farinha & $<3$ & $1 \times 10$ & AUS \\
Pão & $<3$ & $2 \times 10$ & AUS \\
*BRASIL (2001) & $10^{2}$ & $1 \times 10^{3}$ & AUS \\
\hline
\end{tabular}

${ }^{1}$ Coliforme termotolerantes $;{ }^{2}$ Staphylococcus coagulase positiva $;{ }^{3}$ Salmonella $\mathrm{sp} . * * \mathrm{NMP} / \mathrm{g}:$ Número mais provável por grama. *AUS: Ausente. ***UFC/g: Unidade formadora de colônias por grama.

Os dados coletados através das análises microbiológicas da Farinha e Pão de buriti demonstraram que os produtos estão aptos para o consumo, pois apesar de ser encontradas colônias de Staphylococcus C.P. estes valores estão abaixo do limite máximo permitido de acordo com a legislação vigente (BRASIL, 2001) apresentando boa qualidade higiênica- sanitária.

\section{Conclusão}

O estudo constatou que a farinha de buriti apresentou resultados satisfatórios, podendo ser uma alternativa de consumo alimentar, e elaboração de subprodutos. Tanto a farinha como o pão apresentou um valor considerável de lipideos e proteinas, proporcionando alto aporte calórico, podendo ser agregado na alimentação diária das pessoas. Ressaltando assim, a importância da valorização de uma matéria prima regional.

\section{Referências bibliográficas}

Batista, J. S., Olinda, R. G., Medeiros, V. B., Rodrigues, C. M. F., Oliveira, A. F., Paiva, E. S. \& Medeiros, A. C. (2012). Atividade antibacteriana e cicatrizante do óleo de buriti Mauritia flexuosa L. Revista Ciência Rural, 42136-141.

BRASIL. (2001). Resolução-Rde no 12, de 02 de janeiro de 2001 . Em i. C. Sanitária.

BRASIL. Resolução RDC n 263 de setembro de (2005), Aprova o "Regulamento técnico produtos de cereais, amidos, farinhas e farelos" constante do anexo desta Resolução. Orgão emissor: ANVISA-Agência de Vigilância Sanitária, Disponivel em: legis.anvisa.gov.br/leisref/public> Acesso em: 03 de junho de 2019

Francis, F. J. (1982). Analysis of anthocyanins. In P. Markakis (Ed.), Anthocyanins as food color (Vol. 1, pp. 280). London, UK: Academic press.

Lage, N. N. (2014). Avaliação do potencial antioxidante da farinha de buriti (Mauritia flexuosa) in vitro e em ratos diabéticos. Escola de Nutrição5-43.

Manhães, L. R. T. (2007). Caracterização da polpa de buriti (Mauritia flexuosa, Mart.) com vista sua utilização como alimento funcional. Master of Science, Universidade Federal do Rio de Janeiro, Seropédica, Rio de Janeiro.

Pregnolatto, W. \& Pregnolatto, N. P. (1985). Normas analíticas do instituto Adolfo Lutz. São Paulo: Instituto Adolfo Lutz.

Sampaio, M. B. (2011). Boas práticas de manejo para o extrativismo sustentável do buriti. Brasília, Brasil: EMBRAPA.

Sampaio, M. B. \& Carrazza, L. R. (2012). Manual tecnológico de aproveitamento integral do fruto e da folha do Buriti. Manual Tecnológico - ISPN, 41-80.

Saraiva, N. \& Sawyer, D. (2007). Análise do potencial econômico e socioambiental do artesanato do buriti em comunidades tradicionais nos Lençóis Maranhenses. VII Encontro da Sociedade Brasileira de Economia Ecológica, 281-23.

Silva, N., Neto, R. C., Junqueira, V. C. A. \& Silveira, N. F. A. (2005). Manual de Métodos de Análise Microbiológica de Alimentos e da Água (Vol. 1). Campinas, São Paulo, Brazil: Varela.

Recebido: 19 de junho, 2020.

Aprovado: 15 de julho, 2020

Publicado: 29 de fevereiro, 2020.

Licenciamento: Este artigo é publicado na modalidade Acesso Aberto sob a licença Creative Commons Atribuição 4.0 (CC-BY 4.0), a qual permite uso irrestrito, distribuição, reprodução em qualquer meio, desde que o autor e a fonte sejam devidamente creditados. 